\title{
СЮРПРИЗЫ ОТ АНТИТЕЛ ИЗ ДИАГНОСТИЧЕСКИХ НАБОРОВ: ИССЛЕДОВАНИЕ СПЕЦИФИЧНОСТИ С ПОМОЩЬЮ СИНТЕТИЧЕСКИХ ОЛИГОСАХАРИДОВ
}

\author{
Н.Э. Нифантьев, В.Б. Крылов \\ Лаборатория химии гликоконъюгатов, Институт органической химии \\ им. Н.Д. Зелинского РАН, 119991, Москва, Ленинский проспект 47.
}

DOI: 10.19163/MedChemRussia2021-2021-185

E-mail: nen@ioc.ac.ru

Значительное распространение грибковых заболеваний становится всё более и более серьезной мировой проблемой. Смертность от грибковых инфекций в мире сопоставима со смертностью от туберкулеза и сегодня составляет несколько миллионов случаев в год. Ввиду высокой летальности и отсутствия специфических клинических проявлений, важнейшим условием успешного лечения микозов является их ранняя диагностика. Однако представленные сегодня на рынке наборы для иммуноферментного анализа (ИФА используются наиболее широко для диагностики грибковых инфекций) имеют недостаточную специфичность. Их ключевыми компонентами являются моноклональные антитела, информация об эпитопной специфичности которых является основой для понимания природы ложноположительных и ложноотрицательных результатов, а также необходима для совершенствования существующих сегодня диагностикумов.

В большей части грибковых диагностикумов мишенью являются полисахаридные маркеры. Благодаря разработанным эффективным методам стереоспецифичного синтеза антигенных олигосахаридов в нашей лаборатории создана тематическая библиотека лигандов, отвечающих иммунодетерминантным фрагментам полисахаридов клеточной стенки патогенных грибов [1]. Данные соединения и конъюгаты на их основе являются мощным инструментом для генерации, отбора и анализа моноклональных антител. Применение полученных соединений позволило пересмотреть углеводную специфичность у ряда моноклональных антител [2, 3], используемых в известных сегодня диагностикумах, а также получить новые антитела, распознающие маркерные эпитопы [4, 5]. Это, в свою очередь, создало основу для разработки диагностических средств нового уровня. В докладе рассматриваются новые результаты работ в обозначенных направлениях.

Работа выполнена при финансовой поддержке РНФ, проект 19-73-30017.

\section{Литература}

[1] V.B. Krylov, N.E. Nifantiev, Curr. Top. Microbiol. Immunol., 425 (2020) 1-16.

[2] V. B. Krylov, A. S. Solovev, D. A. Argunov, J.P. Latgé, N. E. Nifantiev, Heliyon, 2019, 5, e01173.

[3] V. B. Krylov, A. S. Solovev, I. A. Puchkin, D. V. Yashunsky, A. V. Antonets, O. Y. Kutsevalova, N. E. Nifantiev, J. Fungi, 2021, 7, 504.

[4] A. L. Matveev, V. B. Krylov, L. A. Emelyanova, A. S. Solovev, Y. A. Khlusevich, I. K. Baykov, T. Fontaine, J.-P. Latgé, N. V. Tikunova, N. E. Nifantiev, PloS One, 2018, 13, e0193938.

[5] A. L. Matveev, V. B. Krylov, Y. A. Khlusevich, I. K. Baykov, D. V. Yashunsky, L. A. Emelyanova, Y. E. Tsvetkov, A. A. Karelin, A. V. Bardashova, S. S. W. Wong, V. Aimanianda, J.P. Latgé, N. V. Tikunova, N. E. Nifantiev, PloS One, 2019, 14, e0215535. 